\title{
Assessment of antibiotic sensitivity of the bacterial isolates from patients with bacteremia in Al-Sader Teaching hospital in Amara - Iraq
}

\author{
Younus J. Abdullah ${ }^{1 *}$, Wathiq A. Al-Ramdhan ${ }^{2}$, Mahmood S. Thamer ${ }^{2}$ \\ \{younusjasim@stu.edu.iq ${ }^{1}$, wathiq.alrmadhan@stu.edu.iq ${ }^{2}$, epru@stu.edu.iq ${ }^{3}$ \} \\ ${ }^{1}$ Southern Technical University, Amara Technical Institute, Medical Labs department. Amara city Iraq \\ 2," Southern Technical University, Basra Technical Institute, Environmental pollution Research Unit., Iraq
}

\begin{abstract}
To investigate the incidence of blood-borne infection and to diagnose the causative bacteria and antibiotic sensitivity. Materials. $10 \mathrm{ml}$ of venous blood from (287) febrile patients were collected and subjected to bacterial diagnosis and antibiotic sensitivity test by using Vitek2 tools. Results showed that the incidence of bloodstream infection (BSI) was (54.49\%) and infections were higher in adults and males than children and females. Ten Gram-negative and six Gram-positive bacterial isolates were recovered from positive blood cultures. Antibiotic sensitivity testing of the isolates revealed that vancomycin is the most effective antibiotic against gram-positive isolates while erythromycin is the weakest one. Furthermore, both of imipenem and meropenem exhibit the highest activity against gram-negative isolates, whereas piperacillin and trimethoprim/sulfamethoxazole represent the weakest two. Four Gram-negative isolates were found to resist all antibiotics (MAR index value $=1$ ). In conclusion: Staphylococcus aureus and $\mathrm{E}$.coli are still the most prevalent pathogenic bacteria responsible for bacteremia. Despite the high MAR index values of some isolated species, vancomycin, imipenem, and meropenem found to be the most effective antibiotics against Grampositive isolates and Gram-negative, so it is recommended that these antibiotics could be used empirically, at least in the case where this study was conducted, before performing the culture and antibiogram processes.
\end{abstract}

Keywords: Incidence, Bacteremia, Multiple Antibiotic Resistance (MAR).

\section{Introduction}

Bloodstream infection (BSI) is the abnormal existence of viable bacteria in the circulating blood. The terms bacteremia and BSI are used interchangeably and generally referred to the growth of microorganisms from blood cultures obtained from patients with clinical signs of infection. But the term septicemia referred to the presence and multiplication of bacteria in the bloodstream [1]. These infections may arise secondarily to localized infection at a specific body site or may be classified as primary when no focus is identified. Severe sepsis, septic shock, and multisystem organ dysfunction related to BSI frequently require admission in ICU for appropriate management[2].

BSI is globally associated with morbidity and mortality causing $10-20 \%$ of all nosocomial infections and considered as the seventh cause of mortality in the United States with a rising incidence due to emerging resistant bacterial strains. Mortality rates vary between $10 \%$ and $40 \%$, 
and $25 \%-50 \%$ of all bloodstream infections especially in developing countries where the infection is 3-20 times higher than other countries [3]. Multiple antibiotic resistance (MAR) index calculated as the ratio of a number of antibiotics to which the organism is resistant to the total number of antibiotics to which it is exposed. MAR index values in bacteria are most commonly associated with the presence of plasmids that contain one or more antibiotic resistance genes. MAR index values $>0.2$ indicate high-risk sources of contamination where antibiotics are often used [4].

Although BSI stills a major health problem that causing mortality in Iraq, few previous studies that have focused on this type of infection and no one study was achieved in Amara city, so, the present study aimed to investigate the incidence of BSI as well as demonstrating the antibiotic susceptibility patterns of the isolated bacteria, whereas, the detection of bacteria in the blood is important to establish the presence of infection, assure the clinician about the chosen therapy, and to provide fresh information about antibiotic sensitivities of the etiologic agent, as this will guide the clinician in the management of the patient.

\section{Materials and Methods}

\subsection{Sample size:}

The current study involved (287) febrile patients (150 males, 137 females) who were registered in AL-Sader Teaching Hospital in Amara city, during the period (Jan 2017 - Sept 2017). They were placed into two groups (Children aging 1-12 years old and Adult, older than 12 years old).

\subsection{Bacteriology:}

Under aseptic conditions, $10 \mathrm{ml}$ venous blood samples were collected from all patients then inoculated in BacT/ALERT culture bottles. All blood bottles were incubated aerobically at $37^{\circ} \mathrm{C}$ in the BacT/ALERT system for three consecutive days. During the incubation period, any bottles detected as positive by the BacT/ALERT system were removed, and 3 - 5 drops of the positive sample blood were inoculated to MacConkey agar and blood agar containing 5\% sheep blood. Isolates were identified with the Vitek 2 AES system (bioMérieux, Marcy l'Etoile, France) The Vitek 2 AES system was also used for antimicrobial susceptibility testing. Susceptibility results were interpreted following the European Committee on Antimicrobial Susceptibility Testing (EUCAST) clinical breakpoints (Version 6.0, 2016. (http://www.eucast.org).

\subsection{Determination of multiple antibiotic resistance (MAR) index}

MAR index was determined for each isolate by using the formula $M A R=a / b$, where (a) represents the number of antibiotics to which the test isolate resistance and (b) represents the total number of exposed antibiotics [5]. 


\subsection{Statistical Analysis}

Statistical analyses were done by using the SPSS package software program (Version 20. IBM Corp., Armonk, NY, USA). Descriptive statistics were calculated for all variables.

\section{Results and Discussion}

Table (1) showing that BSI percent reached (54.49\%), males were more infected $(61.22 \%)$ than females (38.78\%). Also, $104(63.03 \%)$ patients were adults, and (36.97\%) children. Previous studies have demonstrated that BSI ranged between (20.9 to $78 \%$ [6-9]. Moreover, there is a gender gap found in susceptibility to some infectious agents and in the adaptive immune response, which has in part a physiological basis in reproductive hormone modulation of immune defense, bacterial virulence, and cell physiology[10].

Table 1. Incidence of bacteremia according to sex and age.

\begin{tabular}{|c|c|c|c|}
\hline \multicolumn{2}{|c|}{ Parameters } & No. & Percent \\
\hline \multirow{2}{*}{ Sex } & Male & 101 & $61.22 \%$ \\
\cline { 2 - 4 } & Female & 64 & $38.78 \%$ \\
\hline \multirow{2}{*}{ Age } & Adult & 104 & $63.03 \%$ \\
\cline { 2 - 4 } & Children & 61 & $36.97 \%$ \\
\hline \multicolumn{2}{|c|}{ Total } & 165 & $54.49 \%$ \\
\hline
\end{tabular}

Figure (1) illustrates that $94(32.75 \%)$ of the bacterial isolates recovered from blood cultures were gram-positive while $71(24.74 \%)$ were gram-negative, however, $122(42.51 \%)$ blood cultures were negative. No fungal or yeast infections were identified.

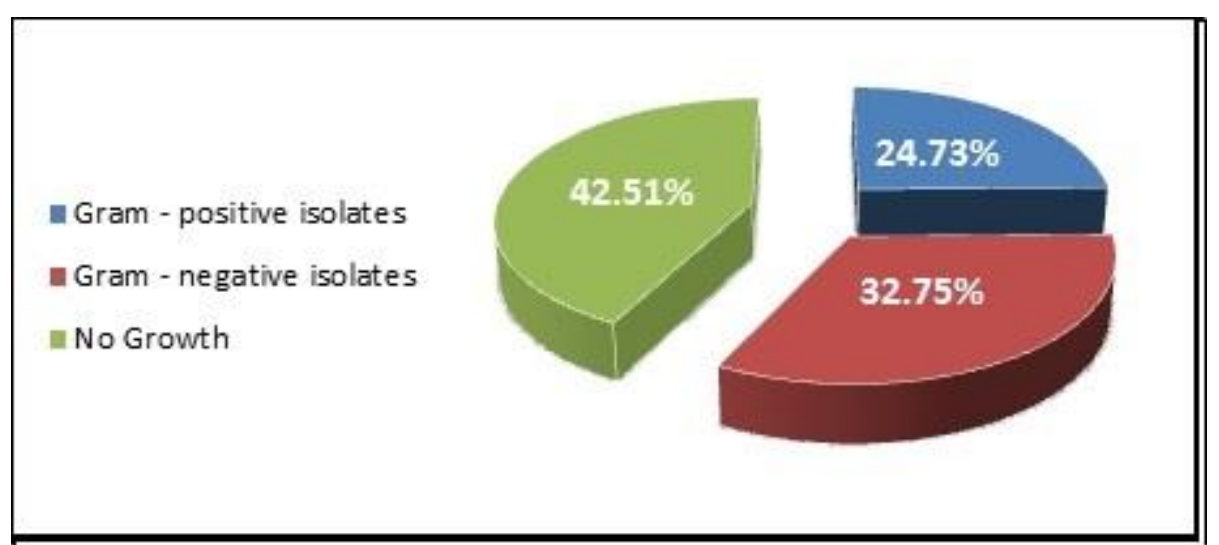

Fig. 1. Percentages of BSI caused by bacteria.

There are ten Gram-Negative bacterial isolates (Acinetobacter baumannii, E. coli, Enterobacter cloacae, Klebsiella pneumoniae, Pantoea agglomerans, Proteus mirabilis, Pseudomonas aeruginosa, Salmonella enterica subsp. Enterica, Serratia marcescens and Sphingomonas paucimoblis) and six Gram-Positive isolates Staphylococcus 
aureus, Staphylococcus hemoluticus, Staphylococcus hominis ssp hominins, Staphylococcus epidermidis, Streptococcus agalactiae, and Enterococcus faecalis were recovered from blood cultures.

$S$. aureus and $E$. coli were found to be the most common pathogenic bacteria responsible for BSI with a percentage of isolation reached $40.42 \%$ and $26.76 \%$ respectively as illustrated in Figures (2,3). That results indicate that $S$. aureus, E. coli, and K. pneumoniae are the significant causes of BSI. Staphylococcus aureus, Streptococcus pneumoniae, and E. coli are the most commonly isolated pathogens associated with BSI worldwide. The epidemiology of BSI varies according to geographic location, age, and co-morbid illnesses. As an example, Salmonella enterica is a frequently isolated pathogen from blood samples in both African and Asian regions $[11,12]$.

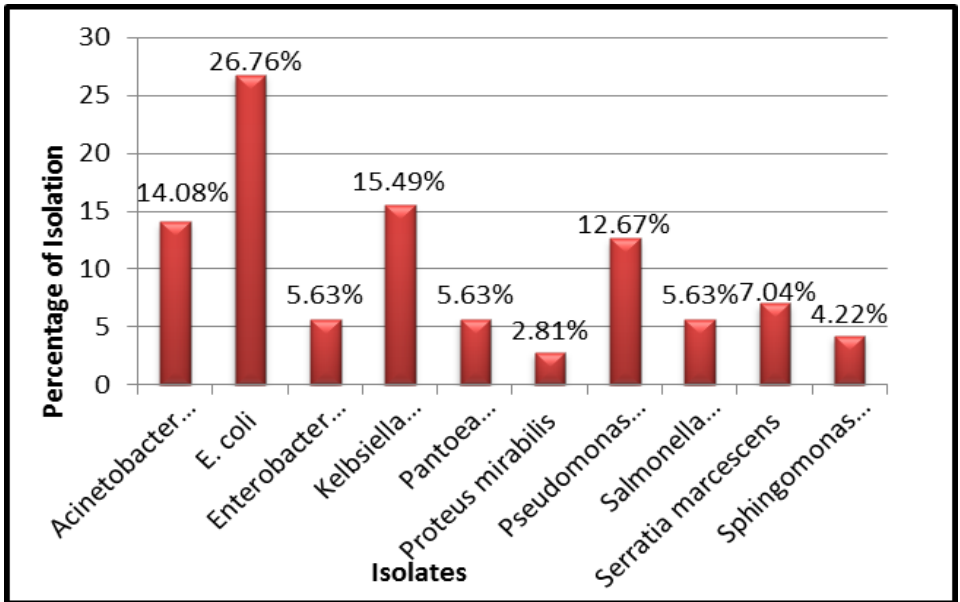

Fig. 2. Percentages of gram-negative bacterial species isolated from patients.

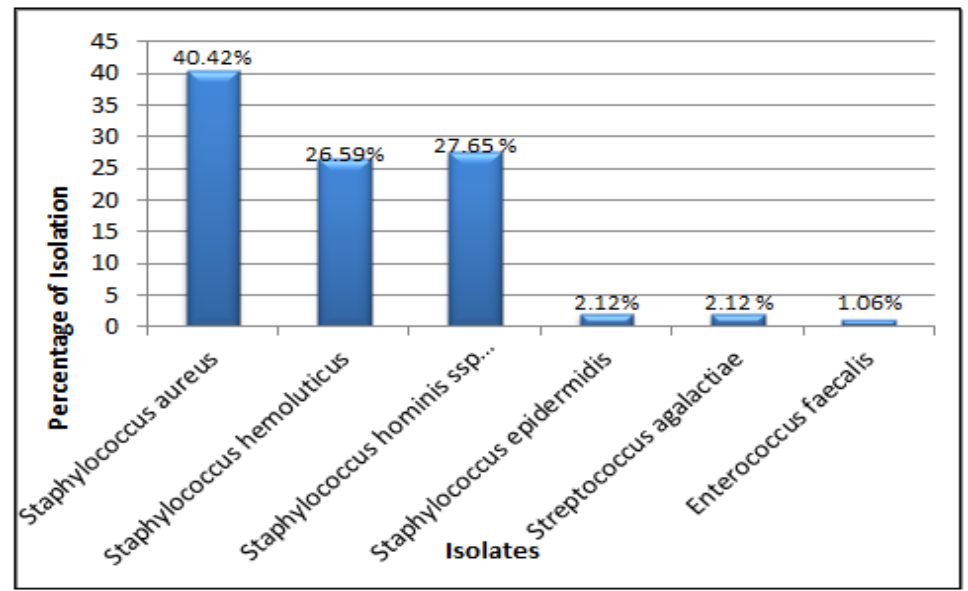

Fig. 3 Percentages of gram-positiveve bacterial species isolated from patients.

From the results of antibiotic susceptibility testing that accomplished by using Vitek2 tools, teicoplanin, vancomycin, and linezolid are the best antibiotics against $S$. aureus, the same activity of these antibiotics observed against S. hominis ssp hominis, S. hemoluticus and other 
gram-positive isolates table(2). However, all gram-positive isolates exhibited a high rate of resistance to erythromycin, hence this antibiotic is considered as the weakest one in this study. These results are appropriate with $[13,14]$ suggesting that later drugs may not be recommended for treating bacterial BSI. Table (3) shows that tobramycin and ciprofloxacin are the best two antibiotics against $A$. baumannii isolates, also, imipenem and meropenem are the best antibiotics against the isolates of E. coli, K. pneumoniae, P. agglomerans, $P$. mirabilis, $S$. enterica subsp. Enteric and $S$. marcescens. Moreover, E. cloacae are sensitive to all used antibiotics, while $P$. aeruginosa exhibits high sensitivity to both amikacin and minocycline, $S$. paucimoblis isolates are also sensitive to minocycline, ceftazidime, and gentamycin. Nevertheless, $(57.89 \%$ and $52.89 \%$ ) of E. coli isolates are resistant to piperacillin and trimethoprim-sulfamethoxazole (SXT) respectively. Likewise, all of $K$. pneumoniae isolates are resistant to piperacillin and ceftazidime, besides, $(72.72 \%)$ of them and $(66.67 \%)$ of $P$. aeruginosa are resistant to SXT. (75\%) of S. enterica subsp. Enterica isolates are resistant to ciprofloxacin. From the obtained results, it can be deduced that the highest rates of microbial sensitivity were to vancomycin, imipenem, meropenem, and amikacin, while, most of the isolates are resistant to erythromycin, tobramycin trimethoprim, and tetracycline.

Sphingomonas paucimoblis isolates exhibit the highest rate of resistance to most of the used antibiotics, as, they are resistant to piperacillin, cefixime, imipenem, meropenem, gentamycin, tobramycin, ciprofloxacin, and SXT. Notably, The present study reported that two (20\%) of $A$. baumannii and two of $K$. pneumoniae (18.18\%) isolates exhibit resistance to all antibiotics listed in table. 3 . It has been estimated that by 2050 resistance will be responsible for 300 million deaths and drain up to $\$ 100$ trillion from the world's gross domestic product $[15,16]$.

Based on our results there is increased emergence of bacterial isolates that are resistant to piperacillin and trimethoprim-sulfamethoxazole (SXT) in the hospital environment. The growing resistance of bacterial species presents in the health care environment my consequently leading to make these antibiotics inactive for treating infectious diseases. We also found that vancomycin, carbapenems, and amikacin were associated with fewer resistance frequencies. Therefore, it is important to control the use of these antibiotics in the hospital setting to prevent the emergence of aminoglycoside- and fluoroquinolone-resistant strains, and to restrict the use of antimicrobials when these resistant strains are detected.

It is clear that overuse and misuse of antibiotics in addition to unavailability of newer drugs attributable to exigent regulatory requirements and reduced financial inducements are the main determinants for the increases in antibiotic resistance in developing countries, like Iraq, which caused variations in the drug resistance profiles of bacterial populations and the emergence of multiple-drug resistant bacteria (MDR) [17].

Mutations, horizontal gene transfer mechanisms, efflux pumps, biofilm resistance \& quorum sensing, and intrinsic resistance are other proposed mechanisms for the growing crisis of antibiotics resistance bacteria in both developed and developing countries [18]. 
Table 2: Antibiotics sensitivity of Gram-Positive isolates

\begin{tabular}{|c|c|c|c|c|c|c|c|c|c|c|c|c|c|c|c|c|c|c|}
\hline \multirow[t]{2}{*}{ Antibiotics } & \multicolumn{3}{|c|}{$\begin{array}{l}\text { S. aureus } \\
\text { (38) isolates }\end{array}$} & \multicolumn{3}{|c|}{$\begin{array}{c}\text { S. } \\
\text { hemoluticus } \\
\text { (25) isolates }\end{array}$} & \multicolumn{3}{|c|}{$\begin{array}{l}\text { S. hominis ssp hominis } \\
\text { (26) isolates }\end{array}$} & \multicolumn{3}{|c|}{$\begin{array}{l}\text { S. epidermidis } \\
\text { Two isolates }\end{array}$} & \multicolumn{3}{|c|}{$\begin{array}{l}\text { E. faecalis } \\
\text { One isolate }\end{array}$} & \multicolumn{3}{|c|}{$\begin{array}{l}\text { S. agalactiae } \\
\text { Two isolates }\end{array}$} \\
\hline & $\% \mathrm{R}$ & $\% \mathrm{~S}$ & $\% \mathrm{I}$ & $\begin{array}{l}\% \\
\mathrm{R} \\
\end{array}$ & $\begin{array}{l}\% \\
\mathrm{~S} \\
\end{array}$ & $\begin{array}{l}\% \\
\mathrm{I} \\
\end{array}$ & $\% \mathrm{R}$ & $\% \mathrm{~S}$ & $\% \mathrm{I}$ & $\begin{array}{l}\% \\
\mathrm{R}\end{array}$ & $\begin{array}{l}\% \\
\mathrm{~S}\end{array}$ & $\begin{array}{l}\% \\
\mathrm{I} \\
\end{array}$ & $\begin{array}{l}\% \\
\mathrm{R} \\
\end{array}$ & $\begin{array}{l}\% \\
\mathrm{~S} \\
\end{array}$ & $\% \mathrm{I}$ & $\begin{array}{l}\% \\
\mathrm{R} \\
\end{array}$ & $\begin{array}{l}\% \\
\mathrm{~S} \\
\end{array}$ & $\begin{array}{l}\% \\
\mathrm{I}\end{array}$ \\
\hline Gental & 1.05 & 3.15 & 15.78 & 68 & 28 & 4 & 11.53 & 73.07 & 15.38 & 0 & 100 & 0 & 100 & 0 & 0 & 0 & 100 & 0 \\
\hline Tobramycin & 15.78 & 81.57 & 2.63 & 44 & 36 & 20 & 7.69 & 88.46 & 3.84 & 0 & 100 & 0 & 0 & 100 & 0 & 0 & 100 & 0 \\
\hline Levofloxacin & 13.15 & 73.68 & 13.15 & 36 & 40 & 24 & 3.84 & 92.3 & 3.84 & 0 & 100 & 0 & 100 & 0 & 0 & 0 & 50 & 50 \\
\hline Moxifloxacin & 5.26 & 86.84 & 7.89 & 8 & 72 & 20 & 7.69 & 88.46 & 3.84 & 0 & 100 & 0 & 0 & 100 & 0 & 0 & 100 & 0 \\
\hline Erythromycin & 73.68 & 26.32 & 0 & 88 & 12 & 0 & 73.07 & 23.07 & 3.84 & 50 & 50 & 0 & 100 & 0 & 0 & 100 & 0 & 0 \\
\hline Clindamycin & 42.1 & 57.9 & 0 & 20 & 76 & 4 & 23.07 & 73.07 & 3.84 & 0 & 100 & 0 & 0 & 100 & 0 & 100 & 0 & 0 \\
\hline Linezolid & 7.89 & 92.11 & 0 & 12 & 88 & 0 & 0 & 96.16 & 3.84 & 0 & 100 & 0 & 0 & 0 & 100 & 0 & 100 & 0 \\
\hline Tiecoplanin & 5.26 & 94.74 & 0 & 8 & 92 & 0 & 3.84 & 88.46 & 7.69 & 0 & 100 & 0 & 0 & 100 & 0 & 0 & 100 & 0 \\
\hline Vancomycin & 2.63 & 94.73 & 2.63 & 4 & 96 & 0 & 0 & 100 & 0 & 0 & 100 & 0 & 0 & 100 & 0 & 0 & 100 & 0 \\
\hline Tetracycline & 39.47 & 60.53 & 0 & 24 & 72 & 4 & 34.16 & 65.38 & 0 & 0 & 100 & 0 & 0 & 100 & 0 & 50 & 50 & 0 \\
\hline Tigecycline & 10.52 & 89.48 & 0 & 12 & 88 & 0 & 7.69 & 88.46 & 3.84 & 0 & 100 & 0 & 0 & 100 & 0 & 50 & 50 & 0 \\
\hline Rifampicin & 15.78 & 84.22 & 0 & 24 & 76 & 0 & 3.84 & 92.3 & 3.84 & 0 & 100 & 0 & 0 & 100 & 0 & 0 & 100 & 0 \\
\hline SXT & 31.57 & 68.43 & 0 & 40 & 60 & 0 & 15.38 & 84.62 & 0 & 0 & 100 & 0 & 100 & 0 & 0 & 0 & 100 & 0 \\
\hline
\end{tabular}

R: Resistant. S: sensitive. I: intermediate sensitive SXT: trimethoprim/sulfamethoxazole.

Table 3: Antibiotic sensitivity of Gram-Negative isolates

\begin{tabular}{|c|c|c|c|c|c|c|c|c|c|c|c|c|c|c|c|c|c|c|c|c|}
\hline \multirow[t]{2}{*}{ Antibiotics } & \multicolumn{2}{|c|}{$\begin{array}{c}{A .^{\mathbf{a}}}^{(10)} \\
\text { isolates }\end{array}$} & \multicolumn{2}{|c|}{$\begin{array}{c}E . \\
(19) \\
\text { isolates }\end{array}$} & \multicolumn{2}{|c|}{$\begin{array}{c}E . \\
(4) \\
\text { isolates }\end{array}$} & \multicolumn{2}{|c|}{$\begin{array}{c}K . \\
(11) \\
\text { isolates }\end{array}$} & \multicolumn{2}{|c|}{$\begin{array}{c}P . \\
(4) \\
\text { isolates }\end{array}$} & \multicolumn{2}{|c|}{$\begin{array}{c}P . \\
(2) \\
\text { isolates }\end{array}$} & \multicolumn{2}{|c|}{$\begin{array}{c}P . \\
(9) \\
\text { isolates }\end{array}$} & \multicolumn{2}{|c|}{$\begin{array}{c}S . . \\
(4) \\
\text { isolates }\end{array}$} & \multicolumn{2}{|c|}{$\begin{array}{c}S . \\
(5) \\
\text { isolates }\end{array}$} & \multicolumn{2}{|c|}{$\begin{array}{c}S . \\
(3) \\
\text { isolates }\end{array}$} \\
\hline & $\begin{array}{l}\% \\
\mathrm{R}\end{array}$ & $\begin{array}{l}\% \\
\mathrm{~S}\end{array}$ & $\% \mathrm{R}$ & $\% \mathrm{~S}$ & $\begin{array}{l}\% \\
\mathrm{R}\end{array}$ & $\begin{array}{l}\% \\
\mathrm{~S}\end{array}$ & $\% \mathrm{R}$ & $\% \mathrm{~S}$ & $\begin{array}{l}\% \\
\mathrm{R}\end{array}$ & $\begin{array}{l}\% \\
\mathrm{~S}\end{array}$ & $\begin{array}{l}\% \\
\mathrm{R}\end{array}$ & $\begin{array}{l}\% \\
\mathrm{~S}\end{array}$ & $\% \mathrm{R}$ & $\% \mathrm{~S}$ & $\begin{array}{l}\% \\
\mathrm{R}\end{array}$ & $\begin{array}{c}\% \\
\mathrm{~S}\end{array}$ & $\begin{array}{l}\% \\
\mathrm{R}\end{array}$ & $\begin{array}{l}\% \\
\mathrm{~S}\end{array}$ & $\% \mathrm{R}$ & $\% \mathrm{~S}$ \\
\hline Piperacillin & 50 & 50 & 57.89 & 42.11 & 0 & 100 & 100 & 0 & 25 & 75 & 50 & 50 & 44.44 & 55.56 & 0 & 100 & 0 & 100 & 100 & 0 \\
\hline Ceftazidime & 50 & 50 & 47.36 & 52.64 & 0 & 100 & 100 & 0 & 25 & 75 & 50 & 50 & 22.22 & 77.78 & 0 & 100 & 20 & 80 & 0 & 100 \\
\hline Cefixime & 40 & 60 & 42.11 & 57.89 & 0 & 100 & 72.72 & 27.28 & 0 & 100 & 50 & 50 & 44.44 & 55.56 & 0 & 100 & 0 & 100 & 66.66 & 33.34 \\
\hline Imipenem & 40 & 60 & 21.05 & 78.95 & 0 & 100 & 27.28 & 72.72 & 0 & 100 & 0 & 100 & 33.33 & 66.67 & 0 & 100 & 0 & 100 & 66.66 & 33.34 \\
\hline Meropenem & 40 & 60 & 21.05 & 78.95 & 0 & 100 & 27.28 & 72.72 & 25 & 75 & 0 & 100 & 33.33 & 66.67 & 0 & 100 & 0 & 100 & 66.66 & 33.34 \\
\hline Amikacin & 40 & 60 & 21.05 & 78.95 & 0 & 100 & 36.36 & 63.64 & 0 & 100 & 0 & 100 & 22.22 & 77.78 & 50 & 50 & 0 & 100 & 0 & 100 \\
\hline Gentamycin & 40 & 60 & 47.36 & 52.64 & 0 & 100 & 36.36 & 63.64 & 0 & 100 & 50 & 50 & 44.44 & 55.56 & 50 & 50 & 40 & 60 & 66.66 & 33.34 \\
\hline Tobramycin & 20 & 80 & 47.36 & 52.64 & 0 & 100 & 36.36 & 63.64 & 0 & 100 & 50 & 50 & 33.33 & 66.67 & 50 & 50 & 0 & 100 & 66.66 & 33.34 \\
\hline Ciprofloxacin & 30 & 70 & 42.11 & 57.89 & 0 & 100 & 36.36 & 63.64 & 0 & 100 & 50 & 50 & 33.33 & 66.67 & 75 & 25 & 0 & 100 & 66.66 & 33.34 \\
\hline Minocycline & 40 & 60 & 31.57 & 68.43 & 0 & 100 & 45.45 & 55.56 & 0 & 100 & 50 & 50 & 22.22 & 77.78 & 0 & 100 & 20 & 80 & 0 & 100 \\
\hline SXT & 40 & 60 & 52.64 & 47.36 & 0 & 100 & 72.72 & 27.28 & 0 & 100 & 100 & 0 & 66.67 & 33.33 & 0 & 100 & 40 & 60 & 66.66 & 33.34 \\
\hline
\end{tabular}

The results of the MAR index, seen in the table (4), showing that four Gram-Negative isolates (two of Acinetobacter baumannii and two of Klebsiella pneumoniae) have MAR index value $=1$. Also, the MAR index of $E$. coli was between $(0.0-0.9), P$. mirabilis $(0.0-0.7), P$. aeruginosa $(0.0-0.9), S$. enterica sub-Enterica and $S$. marcescens $(0.0-0.8)$ and $\mathrm{S}$. paucimoblis $(0.0-0.8)$. Similarly, the $S$. aureus isolates exhibit MAR index ranged between $(0.0-0.7)$, while MAR index of other Staphylococci was $(0.0-0.6)$, moreover, the value was $(0.0$ and $0.0-0.3)$ for both of $S$. agalactiae and $E$. faecalis respectively. In the study of Sandhu et al 2016[5], about 3.2\% of Acinetobacter spp. had MAR index of 1.0 and 83 of isolates (total number $=93$ ) had MAR index equal or greater than 0.2. In addition, 
Bhuvanesshwari, 2017[4] also revealed that six isolates of Acinetobacter spp. had MAR index of one, and 19 out of 45 isolates had MAR index greater than 0.2 .

Table 4. MAR index of the bacterial isolates recovered from blood cultures

\begin{tabular}{|c|c|c|c|c|c|c|c|c|c|c|c|}
\hline \multirow{3}{*}{ Organism } & \multicolumn{11}{|c|}{ MAR Index Value } \\
\hline & 0.0 & 0.1 & 0.2 & 0.3 & 0.4 & 0.5 & 0.6 & 0.7 & 0.8 & 0.9 & 1 \\
\hline & $\mathrm{N}$ & $\mathrm{N}$ & $\mathrm{N}$ & $\mathrm{N}$ & $\mathrm{N}$ & $\mathrm{N}$ & $\mathrm{N}$ & $\mathrm{N}$ & $\mathrm{N}$ & $\mathrm{N}$ & $\mathrm{N}$ \\
\hline E. coli & 8 & 1 & 1 & 2 & 1 & 0 & 2 & 1 & 2 & 2 & 0 \\
\hline A. baumannii & 6 & 1 & 0 & 0 & 0 & 0 & 0 & 1 & 0 & 1 & 2 \\
\hline E. cloacae & 4 & 0 & 0 & 0 & 0 & 0 & 0 & 0 & 0 & 0 & 0 \\
\hline K. pneumoniae & 1 & 0 & 3 & 2 & 2 & 0 & 0 & 0 & 0 & 1 & 2 \\
\hline P. agglomerans & 4 & 0 & 0 & 0 & 0 & 0 & 0 & 0 & 0 & 0 & 0 \\
\hline P. mirabilis & 1 & 0 & 0 & 0 & 0 & 0 & 0 & 1 & 0 & 0 & 0 \\
\hline P. aeruginosa & 3 & 2 & 1 & 0 & 0 & 0 & 0 & 1 & 0 & 2 & 0 \\
\hline $\begin{array}{l}S . \\
\text { enterica subsp. Enterica }\end{array}$ & 1 & 2 & 1 & 0 & 0 & 0 & 0 & 0 & 0 & 0 & 0 \\
\hline S. marcescens & 3 & 2 & 0 & 0 & 0 & 0 & 0 & 0 & 0 & 0 & 0 \\
\hline S. paucimoblis & 1 & 0 & 0 & 0 & 0 & 0 & 0 & 1 & 1 & 0 & 0 \\
\hline S. aureus & 15 & 5 & 6 & 6 & 2 & 1 & 2 & 1 & 0 & 0 & 0 \\
\hline S. hemoluticus & 5 & 5 & 2 & 6 & 2 & 2 & 3 & 0 & 0 & 0 & 0 \\
\hline S. hominis ssp hominis & 12 & 7 & 4 & 2 & 1 & 0 & 0 & 0 & 0 & 0 & 0 \\
\hline S. epidermidis & 1 & 0 & 0 & 0 & 0 & 0 & 0 & 0 & 0 & 0 & 0 \\
\hline S. agalactiae & 1 & 0 & 0 & 0 & 0 & 0 & 0 & 0 & 0 & 0 & 0 \\
\hline E. faecalis & 0 & 1 & 0 & 1 & 0 & 0 & 0 & 0 & 0 & 0 & 0 \\
\hline
\end{tabular}

The MAR index is a good tool for health risk assessment which identifies if isolates are from a region of high or low antibiotic use. A MAR index w 0.2 indicates a 'high-risk' source of contamination. Such an analysis gives an idea of the number of bacteria showing antibiotic resistance in the risk zone of the susceptibility study[19].

In low resource settings, antibiogram along with MAR index serve an important epidemiological tool to monitor drug resistance in bacterial species among inpatients as it is becoming more difficult to treat these pathogens due to the restricted pharmaceutical and therapeutic armamentarium [20].

\section{Conclusion}

We found that $S$. aureus and E. coli are still the classical causative agents of BSI in Amara city as in other regions. Vancomycin, imipenem, and meropenem are the best antibiotics against bacterial strains associated with BSI. Therefore, it is important to control the use of these antibiotics in the hospital setting to prevent the emergence of aminoglycoside- and fluoroquinolone-resistant strains, and to restrict the use of antimicrobials when these resistant strains are detected. There is growing resistance to piperacillin and SXT as they are strongly inactive against bacterial isolates recovered from blood cultures in this study and couldn't be recommended to BSI therapy. The present study cited the diagnosis of drug-resistant Gramnegative Acinetobacter baumannii and $K$. pneumoniae (MAR index value $=1$ ) isolates 
recovered from blood cultures suggesting the need for molecular studies to detect the prevalence of multi-drug resistance gene in hospitals.

\section{References}

[1] Giamarellos-Bourboulis, E. J., Opal, S. M. The role of genetics and antibodies in sepsis. Annals of translational medicine, Vol. 4, (2016)

[2] Goto, M., and Al-Hasan, MN. Overall burden of bloodstream infection and nosocomial bloodstream infection in North America and Europe. Clin Microbiol Infect, Vol. 19, 501-509 (2013)

[3] Vazquez-Guillamet, MC., Vazquez, R., Micek, ST., and Kollef, MH. Predicting resistance to piperacillin-tazobactam, cefepime and meropenem in septic patients with bloodstream infection due to Gram-negative bacteria. Clin Infect Dis, Vol. 65, 1607-1614 (2017)

[4] Bhuvaneshwari, G., Multiple antibiotic resistance indexing of non-fermenting Gram-negative bacilli. Asian J Pharm Clin Res, Vol. 10, 78-80 (2017)

[5] Sandhu, R., Dahiya, S., and Sayal, P. Evaluation of multiple antibiotic resistance (MAR) index and Doxycycline susceptibility of Acinetobacter species among inpatients. Inter J Infect Dis, Vol. 45, 327 (2016)

[6] Al-Husseiny, K. R. Bactermia and septicemia in the children under three years at Al-Nasseria province. Al-Qadisiyah Med J, Vol. 4, 1-10 (2017)

[7] Ali, SM. Performance of VITEK 2 in the routine identification of bacteria from positive blood cultures in Sulaimani pediatrics ' hospital. Iraqi J Sci., Vol. 58, 435-441 (2017)

[8] Al-Turihi, TSA. Epidemiological study of nosocomial bacteremia in Al-Najaf Al-Ashraf. Kufa Med J, Vol. 12, 153-157 (2009)

[9] Al-Marzoqi, AH., Al-Khafagi, AM., Al-Kaqani, M N., Al-Hindi, ZSK., Ewadh, RM., and Al-Jasim, NM. Etiologic agents of bacteremia among newborns in Hilla city. Med J Babylon, Vol. 5, 385-394 (2008) [10] Humphreys, H., Fitzpatick, F., and Harvey, BJ. 2015. Gender differences in rates of carriage and bloodstream infection caused by methicillin-resistant Staphylococcus aureus: are they real, do they matter and why? Clin Infect Dis, Vol. 61, 1708-1714 (2008)

[11] Ahmed, D., Nahid, M. A., Sami, A. B., Halim, F., Akter, N., Sadique, T., ... \& Rahman, M. M. Bacterial etiology of bloodstream infections and antimicrobial resistance in Dhaka, Bangladesh, 20052014. Antimicrobial Resistance \& Infection Control, Vol. 6, 2 (2017)

[12] Buetti, N., Marschall, J., Atkinson, A., and Kronenberg, A. National bloodstream infection surveillance in Switzerland 2008-2014: Different patterns and trends for university and community hospitals. infect control hospital epidemiol, Vol. 37, 1060-1067 (2016)

[13] Opintan, JA., and Newman, MJ. Prevalence of antimicrobial resistant pathogens from blood cultures: Results from a laboratory based nationwide surveillance in Ghana. Antimicrob Resist Infect Control, Vol. 6, 64 (2017)

[14] Thaden, JT., Ruffin, F., Maskarine, SA., Hill-Rorie, JM., Wanda, LC., Reed, SD. and Fowler. Increased costs associated with bloodstream infections caused by multidrug-resistant Gram-negative bacteria are due primarily to patients with hospital-acquired infections. Antimicrobal agents chemother, Vol. 61, e01709-16 (2017)

[15] Akova, M. Epidemiology of antimicrobial resistance in bloodstream infections. Virulence, Vol. 7, 252-266 (2016)

[16] Christopher, AF., Hora, S., Ali, Z. Investigation of plasmid profile, antibiotic susceptibility pattern multiple antibiotic resistance index calculation of Escherichia coli isolates obtained from different human clinical specimens at tertiary care hospital in Bareilly-India. Ann. Trop. Med. Public Health. Vol. 6, 258289 (2013)

[17] Aslam, B., Wang, W., Arshad, MI., Khurshid, M., Muzammil, S., Rasool, MH., Nisar, MA., Alvi, RF., Aslam, MA., Qamar, MU., Salamat, MK. Antibiotic resistance: a rundown of a global crisis. Infection and drug resistance. Vol. 11,1645 (2018)

[18] Junaid, A., Rafiq, Q.A. and Ratcliffe, E. Antimicrobial resistance mechanisms and potential synthetic treatments. Future science OA 4.4 FSO290 (2018)

[19] Davis, R., and Brown, P.D. Multiple antibiotic resistance index, fitness and virulence potential in respiratory Pseudomonas aeruginosa from Jamaica. Journal of medical microbiology 65.4, 261-271, 
(2016)

[20] Sandhu, R., Shalley D., and Pallavi S. Evaluation of multiple antibiotic resistance (MAR) index and Doxycycline susceptibility of Acinetobacter species among inpatients. Indian Journal of Microbial Research, Vol. 3 299-304 (2016) 